\title{
G-SMAC (Social, Mobile, Analytics and Cloud Computing) -A Paradigm Shift in E-Governance Agility
}

\author{
Nitin Yadav \\ Manager, DIMTS \\ J-1503 Divine Meadows \\ Sector 108 Noida- 201301
}

\begin{abstract}
Social, Mobile, Analytics and cloud computing are the flour pillars of SMAC technology which is in collaboration is a key for the next wave of IT transformation. These four pillars are touching every aspect of citizens and government. Social media gives the power of connect, Mobile touches the end user with interactive services which is fast \& easier, analytics help to develop meaningful insight on data and cloud provide data portability, scalability, security and reliability of services at lower cost.
\end{abstract}

\section{General Terms}

E-Governance Agility, Social Networking Sites, Micro Blogs, SMAC, Social and Mobile Analytics

\section{Keywords}

SMAC, Social, Mobile, Analytics, Cloud Computing, PaaS, IaaS, SaaS

\section{INTRODUCTION}

The Social, Mobility, Analytics and Cloud computing, is integrated Technology solution, dependent on four desecrates platforms which are enhanced with high velocity during the last few years and achieved enormous expansion. The world has treated AMAC as integrated technology solution instead of treating these four technology separately. The government is also not an exception for the use of new emerging technology like SMAC [1]. With the advancement in technology, Governments start adopting new technologies but mostly are working in silos and there are limited integration between these technologies which has limited their use for faster execution of Government services.

This generate the requirement of integrated technology model SMAC, which is a combined use of Social media, Mobile, Analytics and Cloud Computing, where Social help in connecting Government with Citizens, Mobile provides faster and easier connection, Analytics provide precise and actionable insight on data through the use of common infrastructure which is Cloud [2].

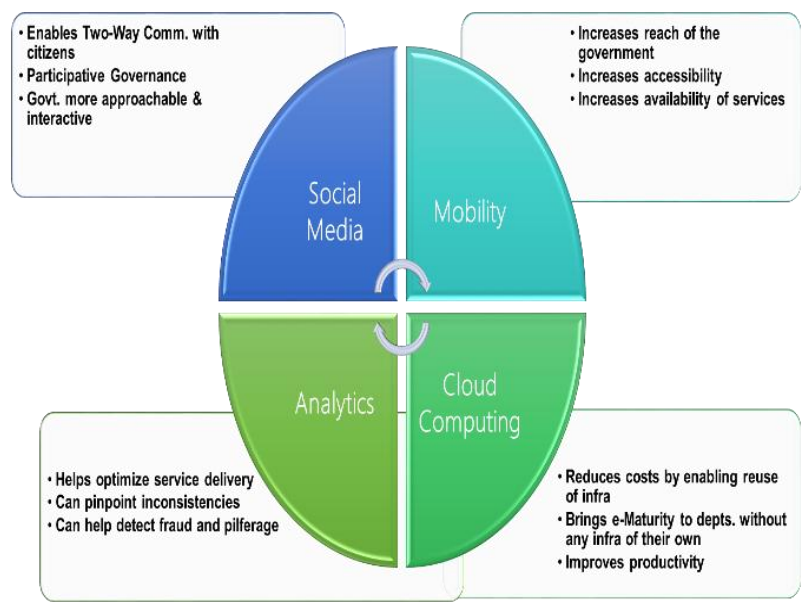

Figure 1: Facets of Transformed Government (SMAC)

\section{G-SMAC IN E-GOVERNANCE AGILITY}

\subsection{Social Media}

The social media gives a power of collaboration, empowerment and participation to the users. This has attracted government to use the power of social media in governance for bringing agencies, citizens and information at a single platform. The government has used it effectivity to promote e-services, transparency and develop trust in government policies. Social media helps to improve quality in governance and reduced the cost of connect with citizens. The government is using the social media to promote services, seek public feedback, opinion on public policies, and advertisement of their work. Citizens want to connect with the government to know about any changes in the policy or update which can affect citizen's life. Digital India is using Social channels such as facebook, twitter, you tube, Instagram and Linkedin to communicate with their government. This has increased the transparency in government processes and operations which in turn develop trust on government [3].

\subsubsection{Type of Social Media}

The social media tools available and use by government are as follows [11]:

Table 1: Social Media Tools use by Government

\begin{tabular}{|l|l|}
\hline Platform & Description \\
\hline $\begin{array}{l}\text { Social } \\
\text { Networking Sites }\end{array}$ & $\begin{array}{l}\text { Social Networking sites facilitates of } \\
\text { the sharing of chat, photos, instant } \\
\text { messaging, updates, etc. Facebook is } \\
\text { the most prominent social } \\
\text { networking sites }\end{array}$ \\
\hline Blogs & $\begin{array}{l}\text { Blogs pages are created and } \\
\text { maintained by individual users and }\end{array}$ \\
\hline
\end{tabular}




\begin{tabular}{|l|l|}
\hline & $\begin{array}{l}\text { contain text, links to web sites and } \\
\text { photos. The interactive feature of } \\
\text { the blog is to write a comments and } \\
\text { that comments trail can be followed } \\
\text { by users. }\end{array}$ \\
\hline Microblog & $\begin{array}{l}\text { The Microblogs and blogs are alike } \\
\text { but has a typical restriction of 140 } \\
\text { char. or less. Twitter is well known } \\
\text { microblogging site which allows } \\
\text { users to write content and share. }\end{array}$ \\
\hline $\begin{array}{l}\text { Video Sharing } \\
\text { Vles }\end{array}$ & $\begin{array}{l}\text { The blogging site support Video } \\
\text { with text. Largest video sharing site } \\
\text { is YouTube. }\end{array}$ \\
\hline Wikis page & $\begin{array}{l}\text { It is a collaborative website to } \\
\text { allow several users on particular or } \\
\text { interlinked subjects to create and } \\
\text { update pages }\end{array}$ \\
\hline
\end{tabular}

\subsection{M- Governance}

The rapid growth of mobile phone users has provided opportunity for government to adopt m-Governance framework to utilize the potential use of mobile applications to access the government information and provide interactive government services. The framework has leveraged available wireless network and growing social media technology platforms, mobile phone devices and Mobile applications for delivery of information and services to citizens.

The Government has adopted the One Web Approach to make available same information and services to citizens, irrespective of the different devices or browsers. This create the requirement that all Government Web sites should be mobile compliant to assist users to access the same information and services from any hardware devices.

The pre-requisite for the adoption of M-Governance is to analyse the model of Mobile Government Value Chain model which involve government entities, wireless operators, Independent Hardware vendors, communication infrastructure providers [5].

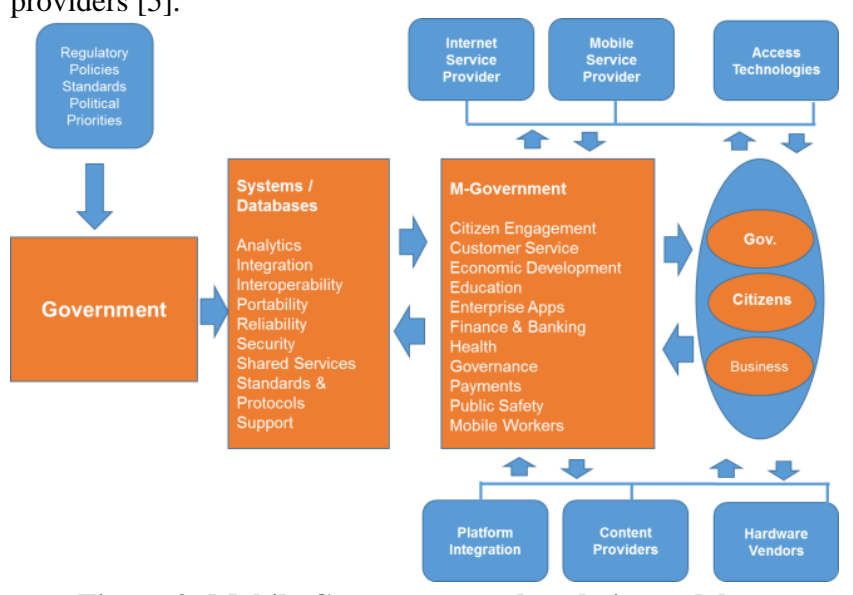

Figure 2: Mobile Government value chain model

\subsubsection{Core Infrastructure- Mobile Services Delivery Gateway (MSDG)}

The MSDG centralize platform is a key enabler for the implementation of m-governance in India. The framework has provided the rapid development in the field of Mobile
Governance. The MSDG is one stop solution which was created for the use of shared technical infrastructure. The platform is the solution for the all central \& state government department to enable the use of mobile application with the common e-Governance infrastructure without investing in separate mobile platform. The interoperability is the core function of the MSDG platform across various public departments to reduce the total cost of operation of $\mathrm{m}$ Governance implementation. The platform uses the cloud computing for the hosting requirements of application and developed on open standards.

\subsubsection{E- Government Agility through M- Governance}

The M-Governance platform that enable the interaction between government and citizen for faster delivery of services and easier in day to day operation. The system help the citizens to stay connected with their government about their policies, government announcements, government information, ask questions, process their transactions, report problem with government and to get the emergency assistance form government departments [10].

The M-governance provide valorous channels of communication to public for the interaction with the government -such as SMS (short Message Service, Social Media tools, IVR, IVVR (Interactive Voice and Video Response) and Wireless Access Protocol (WAP) for two way communication [4].

The M-Governance services are categorized as:

- Interactive services

- Citizen Engagement and Governance

- Transactional Services

- Information Services

A. Informational Services (Push Services)

This type of Government to Citizen Services where Government want to disseminate information to Citizens related to change in policy, Services, Regulations, Education services. The service is based on push information either through SMS or IVR calls. These type of information where most of the content are static. Most of the Center and State government Department in India have integrated their services with MSDG platform for Bulk Message delivery and user specific delivery of information.

Information Services in this category are:

- Health and Safety Services (Prevention and Preparedness)

- Education Services

- Emergency Services like Severe Weather, Fire, Earthquake, Terrorism etc.

- Social Media Post, RSS feeds for Government News and updates

- Specific information like Road Closure, Holiday, Service and fee changes related information.

B. Interactive Services

This type of Government to Citizen Services where citizen can initiate a dialogue with government and send their queries with specific department, problem, and comments on government policy related matters. This type of communication is one-to-one communication where focus is on citizen convenience and their participation. The many government departments are using the Interactive Voice Response System for increase the quality level of service 
delivery. The Indian Railways is using this system very effectively. The system is collecting real time feedback from passengers for their travel.

Interactive Services in this category are:

- Feedback or Survey

- Health services

- Education services (exam result, admission etc.)

- Security services (law \& enforcement, emergency assistance requests etc.)

- Enquiry services (traffic and transportation availability, service request etc.)

C. Transactional Services

This type of Government to Citizen Services where citizen can complete the online transactions with government at their convenience. These services includes paying of government taxes, income tax, property tax and other government to citizens services with convenience and availability of $24 X 7$.

Transactional Services in this category are:

- $\quad$ Taxes \& duties ( income tax, government duties)

- Government Department Bills for Electricity \& Water etc.

- Gov. Employment Services

- Government programmes

- Transportation services

D. Governance and Citizen Engagement

The objective of connected government is citizen engagement and increase participation in government policies, strategy formulation. The mobile gives power to get connected with one another and government through SMS, social mobile Apps which is effective foundation of M-government and gives a positive impact of democratic process of Government [7].

\subsection{Analytics: Moving towards a data- driven culture of governance}

Today Governments across the world are sitting on pile of data about their citizens. This is also true for fast-developing country like India, which is going through the raid digitalization for better service delivery of essential services like banking, education, healthcare, transportation to their citizens. The digital India program aim towards the digitally empowered society and making an integral part of governance system.

The digital India is the need of the hour, therefore, to tap this unparalleled opportunity in the form of massive information, analytics help to leverage this vast data into meaningful information for effectivity utilization of resources in public interest and improve the operation and transparency of government system
The potential uses of data analytics is available in government with the help of mobile and social media tools in the formation of government policy making and big decisions [8].

\subsubsection{Application (Data Analytics) Scenarios in e-Governance}

A. Tax Administration

The data analytics helps in providing precise and actionable information on Tax evasion cases. The Government has launched project insights which is an advanced analytics project with a comprehensive integrated platform to promote voluntary compliance and prevent the non-compliance in income tax. The platform helps to detect fraud, support investigation in case of tax evasion. The system is in use by Indian government and also used at the time of demonetization.

B. Subsidy Programmes

The government can tackle the problem of subsidy outreach to the rightful individuals with the power of analytics. The government is using geotagging assets under MGNREGA which is the biggest social security program in India. The analysis of the data generated through the system helps in bringing accountability and transparency. The data generated through the system will be used to bolster programs and help to prevent misuse assets. Approx. 10 million assets are geotagged and bring in public domain.

\section{Law and Order}

The government is using Predictive models to identify 'hot spots' of crime based on the historical crime data. The analytics platform can also help in identifying the community behavior in respect of crime and various activities can also be modeled with the use of advanced data analytics.

D. Public Safety

The use of SMAC helps to detect patterns of possible threat related to public safety with the help of social media post, mobile uses and big data analytics. The Analyst working on security related matters are able to detect patterns related to civic violations, malfunctioning and relay to keep filed officials informed.

\section{E. Transportation}

The government is using predictive analytics with the help of data coming from valorous sources to analyse the transportation condition in cities. This helps to detect traffic patterns and congestion spots in the city in real time.

\section{F. Healthcare}

The government can use predictive analytics to quantify links between climate changes and diseases outbreaks. The predictive analytics is necessity for our country where monsoon and floods affects every other part of country which bring water borne diseases. 


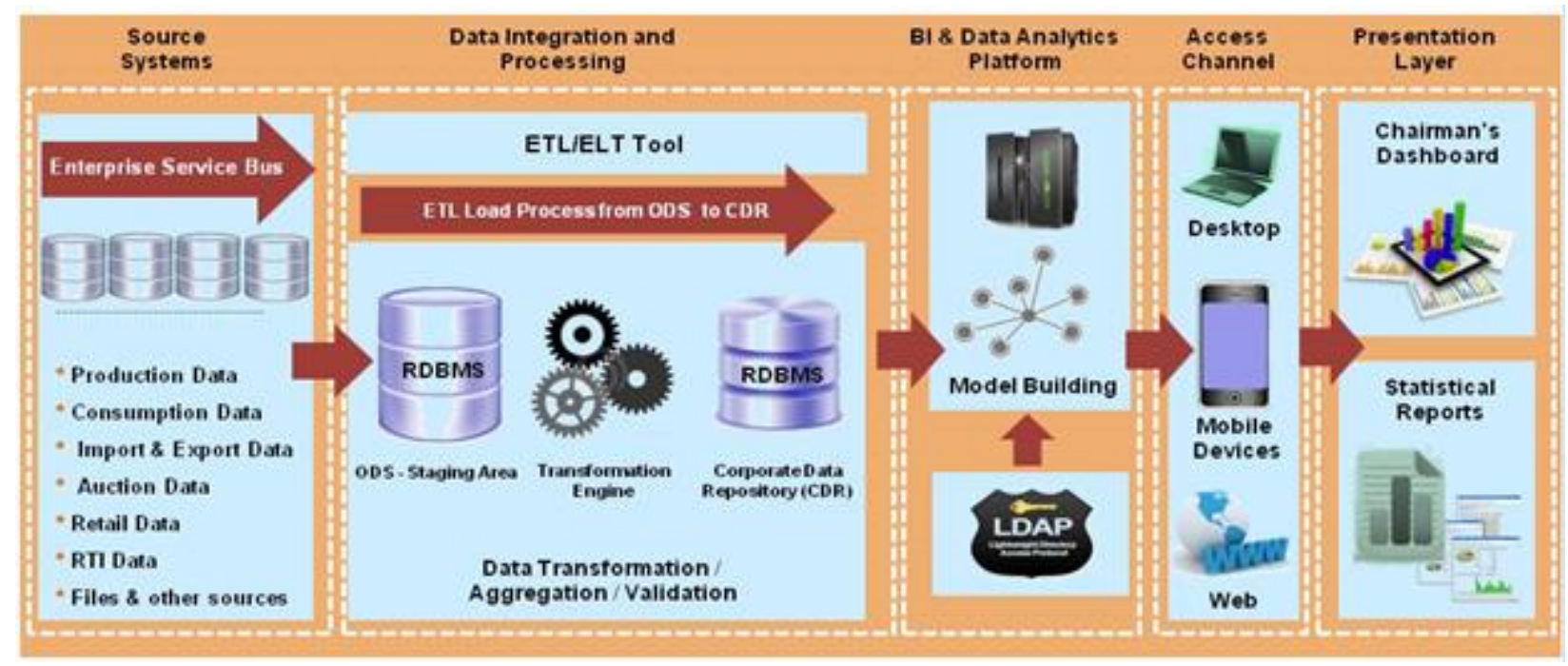

Figure 3: BI \& Data Analytics Solution Architecture

\section{G. Land Use}

Government is using analytics to assimilate historical and real time data pertaining to demographics, citizen grievances, crime patterns, environment condition, flooding to identify the need of Hospitals, Police stations, Common Service Centers, Post office, Banks and so on.

\section{H. Smart Cities}

The government has started smart city programme to develop 100 cities across the country a citizen friendly and sustainable city. The future of analytics in governance has taken a new dimensions with initiation of smart city programme. The Analytics will play a key role for effective policy implementation for the development of smart-cities resilient model. The model will be built on increased resilience of infrastructure, business requirements of cities, and against extreme weather conditions; where citizen services and national security are at paramount importance [6].

\subsubsection{BI \& Data Analytics Solution Architecture}

The components of BI include the data source which is on basis of data quality and level of details in data. The BI uses both structured and unstructured data set into a consistent and coherent data set [9].

\section{A. Data collection}

- Identify the data available in the form of structured and unstructured data

- Unstructured data from heterogonous data sources are collected and store in common data repository.

B. Data aggregation \& transformation

- Data will be transform and aggregated

- Data entry

- Clean the data available and examine for the quality of data

C. Data Integration \& pre-processing

Sometimes data collected are incomplete and missing certain attributes. Data pre-processing methods are used to prepare the data into a comprehensible format:

Examine different attributes of data, missing information, corresponding data types, inconsistent information and perform transformation, normalization and standardization of data etc.
- Identify attributes

- Generate several descriptive statistics, once the data is clean.

- Carrying in-depth analysis of the features and identify important features

D. Data Modeling and Dash boarding/Reporting

Develop the engine with descriptive statistics and association rules which can help in identifying the trends and patterns. This helps in building a framework that can generate patterns preceding the input.

E. Reports \& Dashboards

The Summary Report of findings, patterns within the data is prepared and report the final findings.

- Previewing, filtering or sampling data prior to creating visualizations or reports

- Correlation between specific attributes

- Role based access and allow users to filter results by date, time \& various category

- System should display the results in various graphical manner

- The system should have drilldown feature

- Export the results in pdf /excel .csv etc.

SMAC has revolutionized the capabilities of existing systems since it allows infusion and integration of structured and unstructured data together. The unstructured data exists in two forms-text and media. The unstructured text data includes feeds, blogs, social media interaction and documents.

SMAC paradigm based on Social media generates high volume of data, which, again cannot be handled by RDBMS. The velocity of data is very fast and temporal dimension attached with it requires the data to be used immediately so data has velocity.

Government for Sentiment Analysis, Machine Learning and enriching the Data Mining capabilities of existing Data Ware housing and Business Analytics systems. Traditional RDBMS cannot handle big data sets so document Databases known as NoSQL databases are used to handle them. 


\subsection{Cloud Computing}

Owing to the requirement of data portability, security and reliability, the cloud is the right solution to fulfil the current hosting requirement of IT organization \& government which provide all these feature along with the power to reduce the overall cost of hosting. This has made the integral part and first choice of IT industry for hosting services. The government of India is major user of the cloud services and has launched major project like App store which is a marketplace for government applications, Aadhar, IRCTC etc.

The G-Cloud initiative of Government of India is implemented for effective delivery of e-services within India. The initiative is based on the formation of national level policy formation for the implementation \& adaptation of Gcloud at state and center level. The objective is to utilize the existing use of existing infrastructure, reusability and rapid development of common infrastructure, Horizontal and vertical Scalability in terms of hardware resources, reduction in significant investment in central infrastructure.

The government is using G-cloud as a common infrastructure for SMAC architecture to get flexibility and scalability benefits of the cloud. Government is using G-cloud for various e-services such as e- procurement, real time processing, online transactions.

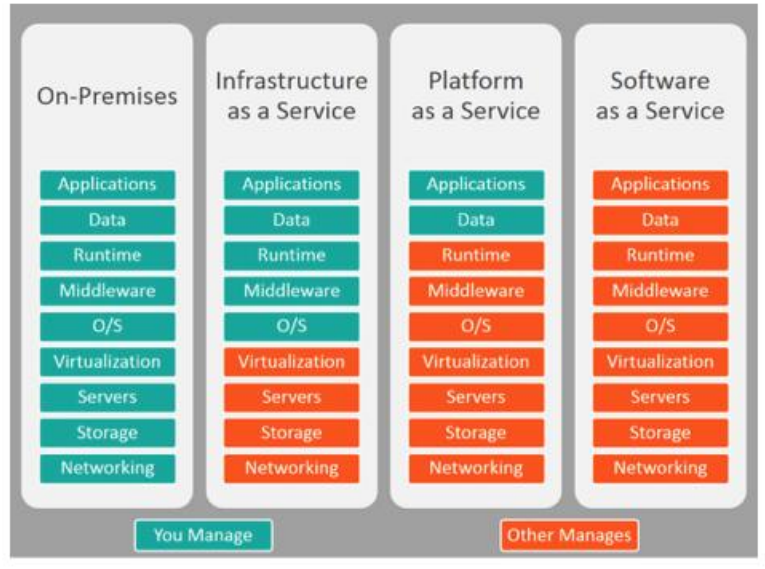

Figure 4: Cloud deployment model (Public, Private, Hybrid \& Community)

\subsubsection{Deployment Model of G-Cloud}

Four type of cloud deployment model is available:

- Public Cloud

- Private Cloud

- Hybrid Cloud and

- Community Cloud

The cloud computing offers various options to deploy application on either shared hardware/resources or exclusively for particular organization or business. The community cloud is one of the variant of hybrid cloud which serve the requirement of specific business communities with common concerns such as Security, Compliance, and Jurisdiction etc.
Government of India has launched a GI Cloud initiative to setup an ecosystem for the adaptation of cloud by government departments.

\section{CONCLUSION}

In today Scenario where time demands that Government should be more committed towards citizens, the government is seeking more insight through the information and data available in their repositories in different system working in silos. The integration of data $\&$ it is required to exploit the use of four pillars of SMAC in collaborative way rather than separately will give better impact of the e-governance service delivery.

The lot of Data is available \& coming in the Government system but it is required to leverage the strength of SMAC in the single envelope to get the citizen delight. Government need to gather data and synthesis the available data at the right time through the collaboration of four technology. At the same time, it is also important to meet the hygiene factor of citizen's data security and privacy. The innovative IT industry gives regular updates to existing technology \& SMAC technology is not an exception.

\section{REFERENCES}

[1] Nicholas D. Evans. SMAC and the evolution of IT

[2] Mr. Hardik Gohel Role of SMAC Technologies in EGovernance Agility

[3] Cable, S. (2011), Citizen-Engaged Communities, Public Technology Institute, 2011.

[4] Dutta, S., Mia, I., the Global Information Technology Report 2010-2011.Transformations 2.0, World Economic Forum, 2011.

[5] Sharma, C. (2008), Mobile Services Evolution 20082018, Chetan Sharma Consulting, Issaquah, WA, USA.

[6] Green Technology: Driving Economic and Environmental Benefit from ICT, World Economic Forum (2009)

[7] Garson, D.G., Public Information Technology and E Governance. Sudbury, MA: Jones and Bartlett Publishers, 2006.

[8] Montgomery Research (2005). Analytics for Tax Collection: From Predictive Models to Optimization.

[9] Agresti, Alan (2002). Categorical Data Analysis. Hoboken: John Wiley and Sons. ISBN 0-471-36093-7.

[10] Bhatnagar, S. (2004). Public service delivery: Does egovernment help, 'Annual Bank Conference on Development Economics, World Bank and NCAER, New Delhi.

[11] Susan Etlinger, Industry Analyst: A Framework for Social Analytics 